\title{
Ultra-reduced phases in ophiolites cannot come from Earth's mantle
}

C. BALlhaus ${ }^{1 *}$, H. HELMY ${ }^{1}$, R.O.C. FONSECA ${ }^{2}$, T.

$\mathrm{NAGEL}^{3}, \mathrm{R}$. WIRTH ${ }^{4}, \mathrm{~A}$. SCHREIBER ${ }^{4}$

${ }^{1}$ Geoscience Institute, University of Bonn, 53115 Bonn, Germany (*correspondence: ballhaus@uni-bonn.de)

${ }^{2}$ Geology, Mineralogy and Geophysics, Ruhr University of Bochum, 44801 Bochum, Germany

${ }^{3}$ Department of Geoscience, Aarhus University, 8000 Aarhus, Denmark

${ }^{4}$ GFZ German Research Centre for Geosciences, 14473 Potsdam, Germany

Until recently it was accepted that ophiolites form at low pressure along intra-oceanic spreading ridges. The identification of ultra-high pressure (UHP) phases in mineral concentrates of chromitites and harzburgites of ophiolite complexes in Tibet, the Polar Urals and elsewhere appears to be changing that view. It is now being argued that the mantle sections of ophiolites either originate in, or were processed within, the Earth's mantle at depths as great as $600 \mathrm{~km}[1,2]$. Furthermore, UHP phases are often found associated with ultra-reduced minerals: native metals, silicides, carbides, and nitrides. The implication is that the mantle source regions of ophiolites, or at least domains within it, must be ultrareduced, so reduced that practically all transition metals are in the metallic state.

We find this notion problematic. The UHP phases and superreduced minerals are mostly recovered from heavy mineral concentrates of podiform chromitite ores or harzburgites, only rarely observed in-situ and then in texturally doubtful association. Thermodynamically, phases like $\mathrm{SiC}, \mathrm{TiC}$, and $\mathrm{Fe}-\mathrm{Si}$ alloys are unstable with $\mathrm{FeO}$ and $\mathrm{Cr}_{2} \mathrm{O}_{3}$ bearing mantle minerals [3]. To illustrate this fact we simulate with piston cylinder experiments at $1300^{\circ} \mathrm{C}$ and $0.7 \mathrm{GPa}$ the reactions that take place when $\mathrm{SiC}$ is compressed and heated together with olivine (Fo90) and chromite, within a redox gradient encompassing more than 12 log-units in fo2. In this redox gradient olivine is reduced to near-pure forsterite and enstatite plus metallic $\mathrm{Fe}$, while trivalent $\mathrm{Cr}$ in chromite is reduced to $\mathrm{Cr}^{2+}$ and metallic $\mathrm{Cr}$ (in Fe metal), causing chromite to break down to a new (yet to be characterised) phase enriched in divalent Cr.

Silicon carbide and other ultra-reduced phases cannot survive in mid-asthenospheric, $\mathrm{FeO}$ and $\mathrm{Cr}_{2} \mathrm{O}_{3}$ bearing mantle for any length of time. The better explanation for these enigmatic phases is that they are plasma condensates, that they precipitated from plasmas generated when lightning struck mantle lithologies of exposed ophiolites [4]. When plasmas condense, the first condensates are oxygen-free precipitates including metals, metal alloys, and carbides if a plasma is $\mathrm{C}$ bearing. Since plasmas can condense on any type of surface, ultra-reduced phases that precipitated from plasmas do not record the origins, emplacement histories or redox states of the lithologies within which they occur.

[1] Griffin et al. (2016) Journ. Petrol. 57, 655-684. [2] Xiong et al. (2015) Gondwana Res. 27, 525-542. [3] Golubkova et al.(2016) Contrib. Miner. Petrol. 171, doi: 10.1007/s00410-016- 1253-9. [4] Ballhaus et al. (2017) Geophys. Persp. Lett. 5, 42-46. 